\title{
Humanitarian Emergencies of Rohingya older people in Bangladesh: A Qualitative Study on Hopes and Reality
}

\author{
Hafiz T.A. Khan \\ Professor of Public Health \& Statistics, College of Nursing, Midwifery and Healthcare, \\ University of West London, Paragon House, Boston Manor Road \\ Brentford, Middlesex TW8 9GB, UK, hafiz.khan@uwl.ac.uk
}

Mohammed Arifur Rahman

Chief Executive, YPSA (Young Power in Social Action), Chittagong-4212, Bangladesh and PhD Fellow, Techno India University, India.ypsa_arif@yahoo.com

Morshed H. Molla

Research and Monitoring Officer, YPSA (Young Power in Social Action), Chittagong-4212, Bangladesh. morshedgeo@yahoo.com

Mohammad Shahjahan

Deputy Director (Head)- Knowledge Management for Development (KM4D), YPSA (Young Power in Social Action), Chittagong - 4212, Bangladesh.jahanctg@gmail.com

\author{
Rifah B. Abdullah
}

School of Psychology, University of Glasgow, Glasgow, Scotland, United Kingdom.

rifahbin@yahoo.co.uk 


\begin{abstract}
The recent influx of Myanmar Rohingya people are allowed in Bangladesh simply due to humanitarian reason, of which older people are amongst the most vulnerable groups. Utilizing integrated methods, the refugee crisis is being managed jointly by various stakeholders. Young Power in Social Action (YPSA) is an NGO that has been providing support to older Rohingya people in the camps since the crisis began through their Age Friendly Support (AFS) centres. These centres provide basic medical treatment, counselling, education, health and wellbeing services, indoor games, and recreational services/activities. Yet, there have not been any studies to understand the expectations of older Rohingya people living in the camps. Thus, the purpose of this paper is to examine the current YPSA support for older Rohingya people living in the Ukhiya camps and to evaluate their expectations for returning to Myanmar. A pilot survey was conducted on $26^{\text {th }}$ April 2019 in two camp sites and in-depth interviews were also conducted with 4 participants ( 2 males and 2 females), followed by a focus group discussion. It emerged that older Rohingya people received necessary support services from these YPSA centres and are generally happy with those services. Although they remain grateful to Bangladesh for sheltering them, they are not as happy compared to their lives back in Myanmar. Most of the older people reported that their expectations involved a return to Myanmar as soon as possible as well as seeking justice from the international community so that the Rohingya crisis could soon come to an end.
\end{abstract}

Keywords: Rohingya older people; Humanitarian assistance; AFS; Cox's Bazar, Bangladesh. 


\section{Introduction}

Extreme violence in Rakhine State, Myanmar has been ongoing since 25 August 2017 and has driven out an estimated 693,000 Rohingya refugees, causing them to flee across the border into Cox's Bazar District in the southern part of Bangladesh. There are currently around 909,919 Forcibly Displaced Myanmar Nationals (FDMN) in Bangladesh (UNHCR, 2019; BBS, 2014). Generations of statelessness have imposed vulnerabilities on these people even before the severe traumas of this most recent crisis. On the other hand, the influx of the Myanmar Rohingya people has created huge strains for the host communities in Ukhiya and Teknaf Upazilas in the Cox's Bazar District. The strains involve socio-economic, cultural, political, and environmental burdens for the Government of Bangladesh.

The people and Government of Bangladesh welcomed them with amazing generosity and opened borders for solely on humanitarian reasons. Bangladesh continued to solve this crisis from the beginning, however has received little support from the international community to help the Rohingya people return to their country of origin (Myanmar).

The speed and scale of the influx was nonetheless a challenge, and the humanitarian community stepped up its support to help mitigate a critical emergency. There have not been any studies to understand the expectations of older Rohingya people living in the refugee camps that were set up in response to the influx. The purpose of this paper is to examine the current Young Power in Social Action (YPSA) support for older Rohingya living in the Ukhiya camps and to evaluate their expectations for returning to Myanmar.

The humanitarian response was also designed to mitigate any impact on the existing Bangladeshi communities that were directly affected by this new influx of migrant refugees and improve their ability to cope with the strains of hosting nearly a million Burmese people. Months later, refugees remain forced to rely upon humanitarian assistance for their basic needs. It represents the world's largest refugee settlement with a population density of 60,000 per square kilometer i.e., one and a half times more than the world's most densely populated city of Manila or four times that of New York City (Sullivan, 2020; Solidarities International, 2020). Temporary houses were constructed mainly from bamboo and plastic sheeting, which are ill-equipped to handle the early monsoon and cyclone seasons. During the monsoon season thousands of these shelters have been flooded or washed away. Additionally, cyclones bring heavy rains that could cause further flooding and landslides (Relief Web International, 2020). 
Many refugees have expressed anxiety about their future in light of media reports about their return, explaining that they would not agree to go back to Myanmar until questions of citizenship, legal rights, access to services, justice, and restitution are addressed. Humanitarian crises affect each person differently depending on their gender, age, disability, and other personal characteristics. Older people, particularly those with disabilities, are often overlooked in humanitarian relief and response, and they may find it harder than others to access the assistance and protection they need. Past research has highlighted potential problems due to influx of refugee migration and suggested medium term solutions for the area (Huang and Gough, 2019).

Bangladesh earned a reputation by temporarily providing asylum to the hundreds of thousands of displaced Myanmar Rohingya nationals. The world sees it positively and the Bangladeshi people are being praised for their humanitarian assistance. The Government of Bangladesh has been working towards the proper repatriation of displaced Myanmar citizens currently living in Teknaf and Ukhia Upazilas of the Cox's Bazar district (BBS, 2014). The Government has been providing various support to all humanitarian activities taking place in those areas with non-governmental organisations (NGOs) also playing an important role through a Rohingya humanitarian assistance programme.

The YPSA, a big NGO in Bangladesh, has been organising various developmental activities in greater Chattogram (Southern geographical region of Bangladesh) since 1985 and implementing similar kind of activities in the Cox's Bazar area since 2008. It has been actively playing an important role in the Rohingya Crisis Response programme since August 2017, when the largest influx of refugees entered Bangladesh. This work has involved the support of UN agencies, especially the World Food Programme (WFP), UNICEF, IOM, UN Women, UNFPA as well as various international development agencies - Action Aid, HelpAge International, Concern Worldwide, Save the Children, and Oxfam. YPSA has also been providing food support for 47,000 Rohingya families in collaboration with WFP and Save the Children. With the support of Action Aid and UN Women, YPSA has established two Women Friendly Spaces and Multipurpose Women Centres. These spaces and centres are providing sewing training, use environmentally friendly fuel, have put up streetlights, provided deep tube wells plus established women-only bathrooms and latrines. In order to help promote and ensure 
the human rights of older Rohingya people who fled to Bangladesh, YPSA has established two age-friendly spaces ${ }^{1}$, with the support of Help Age International (HelpAge International, 2019).

$<<$ Figure 1 about here $>>$

Additionally, YPSA has implemented a project called "Integrated Humanitarian Response to the needs of older men and women amongst Forcibly Displaced Myanmar Nationals (FDMN)." The target group is men and women aged over 60 years ${ }^{2}$ and their families. The purpose was to improve the lives of the elderly by implementing integrated humanitarian services. This project has involved making "Age Friendly Spaces" (AFS) to provide primary health plus Water and Sanitation (WASH) and protection services with the cooperation of HelpAge International, Bangladesh (HAI-BD).

YPSA has been working in two different communities, the Rohingya Camp and host community in Ukhiya, Cox's Bazar. Three AFS in the Rohingya community, namely Camps 11, 12 and 13 and two gender-specific AFS in Rahmater Bill area within the host community. The project has so far included 5,114 older people with 2,550 men and 2,564 women. The total number of older people (60 years or more) in the Rohingya refugee camps is 30,064 with 15,937 men and 14,127 women. The over 60 age category make-up 2 per cent of the total in the 32 Camps in the Cox's Bazar District including Ukhiya and Teknaf Upazilas (UNHCR, 2019). In spite of these numbers, there is no research being conducted about the wellbeing of older people living in the refugee camps. This study is an attempt to redress that situation and also explore the humanitarian contribution of YPSA towards older people living in the Rohingya camps.

The paper is structured into several sections. The next section will focus on Myanmar refugee influx in Bangladesh followed by a methodology, results and discussion. Finally the paper ends up with a conclusion and policy implications.

\footnotetext{
${ }^{1}$ Age-Friendly space is defined, making arrangement for the older male and female Rohingya refugees for staying, spending time with care and supports, services, equally for sharing and exchange.

${ }^{2}$ Owing to poverty, malnutrition, famine, hunger and chronic diseases the elderly people lifetime is little then Bangladeshi people. That's why $>50$ years old people have been considered as a people in Rohingya Refugee camp areas.
} 


\section{Rohingya refugee influx into Bangladesh}

The areas of Ukhia and Teknaf that the Rohingya fled to after the violence of 2017 in Myanmar is bordered on the north by the Ramu and Naikhongchhari Upazila, the Arakan state of Myanmar on the east, and the Bay of Bengal on the south and west. Figure 2 is a map taken from the Bangladesh Refugee Emergency Population factsheet that shows the Rohingya influx area (UNHCR, 2019). There are three-layer local government system in Bangladesh: District, Upazila Parishad, and Union in which Upzila plays an important role in administering Government policies throughout the country.

\section{Research on ageing in the context of Bangladesh and Rohingya elderly refugees}

The population of Bangladesh is estimated to be around 170 million and the country has a population density of 1,115 people per square kilometer, which ranks $10^{\text {th }}$ in the world (World Population Review, 2020). Around 7.3 percent (12 million) of the country's total population constitutes of elderly people (60 years or more), while the number is expected to increase sharply and reach around 22 percent (over 44 million) by 2050 (UN, 2017). The nuclear family unit is increasing with older people often living separately from their families, leading them to becoming vulnerable. This situation demands more from the health and welfare services in providing an appropriate older people support system (Islam and Nath, 2012; Rahman et al., 2009). The Bangladesh Bureau of Statistics (2003) indicated that from 1974 -2001, the number of older people increased from 1.38 million to 7.59 million. Previously, older people in Bangladesh would be taken care of by their families but the situation is changing due to social, psychological, and economic factors that are causing concern for the Government of Bangladesh. The majority of people aged 60 or over live in rural areas that lack proper health care and economic services with very limited job opportunities. The changes in modern society in Bangladesh are leading to failures in maintaining the dignity and honour of its elders. This may be due to various reasons such as individual attitudes, instability of family structures, devaluing of dignity, differences in incomes, and other social problems. In spite of these factors, research focused on the lives of older people in Bangladesh is sparse. There is no specific government department responsible for the wellbeing of older people. The Bangladesh Bureau of Statistics is responsible for finding out the actual figures of older citizens in the whole country but getting accurate figures has so far proved impossible. This situation has been exacerbated by the influx of more than half a million men, women and children from Myanmar, representing the largest mass movement of people seen in the region for decades. These people 
now living in refugee camps are already some of the world's most vulnerable individuals. Moreover, the monsoon rains and the start of the cyclone season in October could make their difficult situations even worse. There could, for example, be an increase in the spread of waterborne diseases, such as cholera, typhoid, and malaria ${ }^{3}$. Most buildings in the camps, including medical facilities, are extremely vulnerable to cyclone damage, such as heavy rains, which could cause further flooding and landslides ${ }^{4}$. The influx of the Rohingya refugees has caused tension between them and the local community. This situation has been compounded by different groups illegally cutting into the hills to establish operational activities and offices for working in the camps thus, making the camps susceptible to landslides (Barua et al., 2019).

$<<$ Figure 2 about here $>>$

\section{Methodology}

The study used narrative analysis with the qualitative data collected from primary sources involving in-depth interviewing and focus group discussions in Rohingya refugee camps. The use of narrative analysis enabled the exploration of the respondent views, opinions, knowledge, experiences, and beliefs. In-depth interviews were conducted with 4 participants involving 2 men and 2 women (Table 1) so that each camp has equal gender balance. Furthermore, we conducted focus group discussions comprising 2 men's groups and 2 women's groups. Focus groups were used to encourage an environment of openness and participant-led discussion. Each focus group consists of around 8 participants. Groups are separate out for gender so that one can compare their views.

$<<$ Table 1 about here >>

Narratives gathered during the interviews were coded and arranged into common themes based on the target respondent, research aim and objectives of the study. For instance, 'humanitarian emergency', 'Rohingya displaced', 'older people', 'awful experience', 'living condition', 
'surviving', 'psychological \& social status', 'feelings', 'future thinking', 'hopes' and 'reality'. These were then used to effectively organize discussion during the focus groups.

Two researchers who were involved in data collection and all data was voice recorded. They then transcribed and translated answers into English, with names changed in-line with ethical guidelines to protect the identity of participants. Translations were cross-checked between both researchers for any inconsistences, ensuring they captured the correct meaning and avoided personal bias. The results of primary source will help to check the authenticity of results from other studies.

A survey using purposive sampling was conducted on $26^{\text {th }}$ April 2019 involving Rohingya Refugee Camps 11 and 13 at Ukhiya Upazila in Cox's Bazar District. This is considered as the study evaluation setting.

The intervention considered here is termed as "YPSA programme activities for the Rohingya older people" in the study area. YPSA provides day long various activities for both older males and females such as indoor games, health and hygiene classes, discussion sessions, and free foods and counselling sessions for them.

As mentioned earlier, since 2017 the YPSA has been one of the first organisations to start working with older people. This project is being undertaken in collaboration with the University of West London, UK. Financial support is provided by the HelpAge International Bangladesh and the Palli Karma Sahayak Foundation (PKSF).

Appropriate YPSA ethical approval procedure was followed in selecting participants and data collection for the study. Those who willingly agreed to participate were only included and no at-risk individuals were considered for the study.

$<<$ Figure 3 about here $>>$

\section{YPSA's Initiatives with Older People in Rohingya Refugee Camps}

YPSA has been working in four areas to promote wellbeing among older people in the Rohingya refugee camps covering health, WASH, protection and capacity building and empowerment. Health-related initiatives have been established in two of the camps with registered physicians and paramedics recruited to carry out the work. These initiatives involved 
the setting up of a primary health service with medicine provided; home base care service for the disabled; psychological counselling and family counselling; referral service for secondary, tertiary service and psychosocial counselling; diabetes testing; haemoglobin testing; nebulizing; disabled patients carrying service; ORT Corner; eye camp and health camp. Other activities include an awareness session about WASH; a hygiene kit demonstration and distribution; toilet and washing point demonstrations; a pure drinking water facility at AFS and advocacy with service providers to establish age-friendly toilets. A major aim of these initiatives was to provide safe drinking water and good hygiene practices among older people living in the camp areas. Protective measures were taken into consideration to ensure the safety of older people in the camps including case management; age friendly kits distribution; winter clothes distribution, and recreational activities. There are links with service providers for humanitarian services such as shelter and NFI, plus for registration, food items, washing items, and health. Capacity building and empowerment-related activities include training on Disaster Risk Reduction (DRR); training on diabetes awareness; observing International Women's Day and International Elderly Day; awareness of diphtheria and chickenpox plus the establishment of various committees and meetings involving older people.

$<<$ Figures 4 \& 5 about here >>

YPSA's Contemporary Performance with Older People in Rohingya Refugee Camps

Since 2017, YPSA has completed 20 types of activities in both camp areas (Table 2). Activities are selected in such a ways aimed at improving their health and wellbeing in old ages.

$<<$ Table 2 about here $>$

\section{Results}

Important results emerged from this study are summarized as follows:

Reality: Friendly spaces for older people in the Rohingya Refugee camps 
The YPSA first established AFS in the Rohingya refugee camps in 2017 and they provide places where older people can meet for conversation and company, helping to reduce isolation as well as help reduce any feelings they may have of being "abandoned, excluded, neglected or rejected". A number of rooms are also set aside for rest and recuperation as needed.

As one older Rohingya refugee commented during the interviews conducted for this research: "After displacement and entering Bangladesh, we are living in a Refugee camp as a general person. At that time we realize we are weighted for all, abandoned, excluded, neglected or rejected in everywhere. After coming to this place, we are happy, since we meet our essential needs, our time with a pool of joyful, we meet each other. Alongside, the authority provides health facilities, recreational facilities, energies and gear up our mind and soul in different ways. Also, they are feeding us (Older Rohingya refugee)."

Another older Rohingya refugee talked about the AFS:

"We are grateful to Bangladesh for sheltering us. The AFS is like my home. Here we are receiving psychological assistance, health care facilities, recreation facilities, and sharing our daily life with each other's. The authority all the time encourages and motivates us. Sometimes we forget that we are displaced from our original places, our country and motherland. We face different types of physical complications; in this regard the authority provides physiotherapy and around-the-clock health care services by registered doctors. We think that, the AFS is paradise for us. But we are worried, how many days will they continue? Sometimes the Rohingya people weep to recall their present life and livelihood. Also the authority provides health screenings and homebased care in the camp community, access to age-friendly latrines, and ensures older people avail the services they need."

$<<$ Figure 6 about here $>>$

\section{Hope: Rohingya People living in refugee camps}

The challenges that the speed and scale of the influx of Rohingya refugees into Bangladesh have provoked and the consequences have been described earlier in this paper. These challenges are being met with strong support from the humanitarian community. Currently, over 100 local, national, and international NGOs are responding alongside the Bangladeshi 
government and UN agencies to deliver protection, food, water, shelter, healthcare, and other life-saving assistance. One year into the crisis, however, the humanitarian community is still delivering emergency aid largely within the framework of "temporary" assistance that falls considerably short of meeting minimum international humanitarian standards ${ }^{5}$. Refugees have reported concerns about violent attacks on the camps, including abductions and kidnappings. In response, many camp authorities have introduced curfews and law enforcement patrols have been increased, particularly at night. The Cox's Bazar area comprises of local communities with already high poverty rates and have also been greatly impacted by the refugee crisis (COAST, 2018).

Despite a general wish of refugees to someday return to their homes in Myanmar, if the conditions of their return are agreed, not all older refugees participating in this study necessarily hold that view.

\section{Bibi, a 70-year-old women who frequently visits an AFS said:}

"By the fairing of Myanmar military my left hand was seriously injured and for a long time I have suffered from this broken hand. After I came here, I felt better because there are people providing health care facilities. Now I have not felt any pain and can move my hand as required. Also they are regularly monitoring the improvement of my hand condition. I am happy here, I am never going back to Myanmar because there's a genocide going on there."

\section{However, Hossan, a 65-year-old man who frequently visits an AFS said:}

"I want to go back to Myanmar if possible. If the International Organization helps to resolve the unrest and killings, and help us go back with proper recognition and dignity, then I will go back."

\section{Aser, a 71-year-old woman said:}

"I am happy and safe here, but I do not belong here. I eagerly want to go back to my homeland where I was born. We are expecting justice from the International community to solve this problem and ensure we are safe after repatriation."

\footnotetext{
${ }^{5}$ https://www.solidarites.org/en/press/one-year-into-the-rohingya-refugee-crisis-in-bangladesh/ (visited 6 May 2019)
} 


\section{FGDs findings}

A summary of FGDs findings is provided here, which further emphasise the themes reflected upon from the interviews and confirm the other results in the study.

Male respondents vocalized the benefits of the AFSs such as enabling socialisation:

"We are injured, scared and upset, but we are happy in present condition. We are thankful to Bangladeshi people, particularly those who are working for us and giving healthcare facilities, feeding, hearing our untold story and entertained us. We easily get together with our old friends during the entertainment period at this center."

However, acknowledge that sharing "memorable times" often incites sadness and even "humiliation", nonetheless they demonstrate hopefulness to return to Myanmar:

"At that time we were sharing our memorable times and horrible situations that happened in our mother land. Sometimes they are weeping, because they have lost their identity, dignity, resources and feel to humiliate to hearing as a 'Refugee'. However, they are dreamy, they believe that they will back their identity, dignity, resources with the help of the international community."

The loss of identity and dignity was a common theme in both FGDs, however female respondents were more distraught and less hopeful regarding the possibility of a return:

"We have lost our family, identity and dignity, while now we are physically safe. Our soul all-time weeping to our motherland, boys, girls, husbands and relatives those who death this genocide. Although, we are physically here now, but everything there. We don't know, when we back? When we see unfamiliar Bangladeshi boys and girls call us mother that time we are soundless. We lost our identity, dignity and kinship in my own land, but we are getting respect in another land. .... drop water from eyes!! May be a few days later we will die, but we want justice! We have complained to the international community why they are committing genocide? Why raped our girls? Why killed our boys and husband? Why we lost our dignity \& identity? Why we displaced from our mother land? Why now we are refugee? May be or may not be we will back to our motherland. We are prayers to Almighty Allah for them those who gives this present opportunity for us." 


\section{Discussion}

The study addresses different issues of Rohingya displaced elderly people, including frightful experience, living conditions before and after displacement, surviving of life, psychological and social status, feelings, future thinking, and hopes as well. Little research has ever been conducted on the Rohingya humanitarian issue in Rohingya camps in Ukhiya and Teknaf Upazilas. By reason of fund crisis and the disinclination of national and international donor agencies, elderly people related initiatives are very limited in Rohingya camp areas. Subsequently, current study is the first to focus solely on exploring the experience and welfare of older Rohingya people during this crisis. As highlighted by Burton and Breen (2002), elderly refugees have more barriers to accessing health and welfare services during crises, than younger individuals, that are often not met by NGOs due to the lack of resources. YPSA is a non-state organization to working for the humanitarian aspects of elderly people to Rohingya displaced people by the financial support of different international organizations.

Results from the study are in line with previous work on the Rohingya crisis (Bhatia et al., 2018; Messner et al., 2019). Participants from both the interviews and focus groups expressed thankfulness to Bangladesh and access to facilities such as AFS for providing an environment where they can feel safe after the trauma of their forced displacement from Myanmar. AFSs appear to provide an avenue to rebuild their social support network in their new environment, which can help improve socio-psychological health outcomes.

However, the trauma of their displacement is acutely felt as shown in the FGDs, especially in older women. Older refugees are more likely to feel the loss of their homeland due to longer attachment, loss of critical social and familial support, and fewer opportunities to assimilate to their new environment (language barriers, lack of job opportunities etc...) (Burton and Breen, 2002). Moreover, the trauma of witnessing violent attacks and mourning the loss of family members result in negative psychological outcomes, which in turn can affect physical health such as nutrition (Strong et al., 2015). Traditionally, older women play an important intergenerational role within the family (Dubus, 2018) as they are more often directly involved in child rearing, cooking and maintaining the household. 
Subsequently, the loss of these and forced displacement may be more keenly felt, which may explain the differences in the use of emotive language between the male and female FGDs.

A growing elderly population in any country carries great social, economic, and public health implications, which include higher expenditure on pension and healthcare, need social security reforms, shrinking of workforce, and hence shortage of active persons who can support older persons (Kabir, 1991; Kabir and Salam, 1993; Kabir, 1994). So far, elderly people related initiatives, humanitarian works, research and elderly people related issues not initialization as well as not very much popular and familiar in Bangladesh. However, traditionally in Bangladesh and in Asia, care for the elderly has been a family responsibility (Khan, 2014; Khan et al., 2017). Due to an unusual rise in the numbers of elderly, several factors may reduce the ability of Asian families to care for the older generation (Saleheen, 2011; Peter, 1997; Linda, 2004; Lucky et al., 2013).

Bangladesh is an over-populated and high-density countries in the Southeast Asian region. Here the state actors cannot ensure the civilian rights at maximum level. Additionally, Bangladesh will face many difficulties in managing the challenges for a large elderly population. This includes factors such as changing family structure from joint family to the increasing number of nuclear families, poverty, social and cultural norms, lack of expertise in geriatric and inadequate health care facilities for the elderly population (Kabir et al., 1993; Kabir, 2003; Rahman, et al., 2007). In these contexts, it is difficult for state and nonstate actors to provide support to elderly people in Rohingya camps for humanitarian aspect.

This work has several issues that need to be addressed in future research.

First, on 27 September 2018, at the $73^{\text {rd }}$ United Nations General Assembly, Bangladeshi Prime Minister Sheikh Hasina said there are 1.1 million Rohingya displaced people now in Bangladesh (UN, 2018), however, there is no clear figure as to how many of them are 60 years and above. To effectively conduct a registration process which enumerates and explores the total number of elderly displaced people from Myanmar and desegregate their gender. So more research is needed in order to capture a clear picture on Rohingya refugee population in Bangladesh. The study only conducts on two camps among 32 camps. 
However, only two non-state organizations have been implemented elderly people related initiatives for the humanitarian aspects across the whole camp areas.

Second, state and non-state actors, including international donor agencies do not seem to be interested to work for elderly people for humanitarian aspects. Though, under the financial support of HelpAge International (as an international organization) YPSA and RIC (Resource International Center) have been implemented limited humanitarian activities in the camp areas. Besides, under the financial support of Palli Karma-Sahayak Foundation (PKSF) (as a partner organization by the government working with life and livelihood for elderly people as a citizen of Bangladesh) YPSA has been implemented life and livelihood related project at two different geographical locations in Bangladesh.

Third, lack of awareness of state actors and development practitioners to working for elderly people in Bangladesh. Nevertheless, YPSA already started the awareness related activities at grassroots level, advocacy with state actors, departments, including with national and international donor organizations, arranging seminars, human chain, leaflet distribution, banner and precession.

There are certain limitations to this research. Research was conducted with participants from the registered refugee camps, which enabled legal protection over those who live in the camps as well as better access to medical aid, food and water and sanitation services. Three out of every four Rohingya refugee outside of Myanmar have not received official refugee status (Mahmood et al., 2017), which limits their access to fundamental resources and increases their risk of violence and abduction (Milton et al., 2017). While research has shown that the consensus for many refugees is to inhabit the camps rather than return to Myanmar (Milton et al., 2017), more research is necessary to understand the thoughts and feelings of elderly Rohingya inhabiting in these camps and whether the possibility of providing initiatives, such as AFSs, is feasible there.

\section{Conclusion}

Bangladesh in general, and Cox's Bazar in particular, are prone to suffer regular severe weather conditions and other disasters (ACAPS, 2018). Influxes of Rohingya refugees into Bangladesh have been occurring since the late 1970s but none has been as large as in 2017. The restrictive policies of the Government of Bangladesh towards registration, freedom of movement, and 
access for organisations that wanted to help the refugees meant that national and local NGOs had limited exposure to and experience of appropriate formal humanitarian responses. The time is coming for proper action to be taken otherwise the situation could turn dire. The findings of this study strongly suggest that the following recommendations will prove very helpful in reducing the severity of the situation and help ensure that there are AFS in the refugee camps for older people. This research indicates that vulnerable Rohingya older people benefits a lot from these AFS initiative as they receive bulk of their day-to-day services through their help. In this worst humanitarian crisis AFS is a rare service for Rohingya older people which demonstrated positive changes of health and wellbeing of older people. The research clearly indicates that there is an urgent humanitarian assistance needed for older refugees and this may be application to anywhere in the world either in conflict zones or minority communities in a country.

The recommendations from this study are as follows:

\section{A considerable increase in funding from donors to help alleviate the crisis -} Bangladesh is one of the least developed countries in the world with large numbers of the populace living under the poverty line. The influx of the Rohingya refugees has added considerably to this situation. Moreover, assistance from the global community and grants from NGOs are essential to prevent the refugee camps and their surrounds from becoming breeding grounds for terrorism, trafficking, smuggling, and drug peddling.

2. Strengthen efforts around accountability - the Bangladesh Government should reinforce accountability at every phase. In doing so, it would minimise the gaps that currently exist between Government and implementing stakeholders. The Government is the sole agent for ensuring accountability across the whole territory.

3. Expand humanitarian aid - due to the influx of Rohingya refugees, the people in the host areas are losing their livelihoods, and finding it difficult to survive in their place of origin. Donor agencies have concentrated their efforts on the wellbeing of the refugees but in order to provide equity for all, these agencies should also cover the wellbeing of people in the host community under their humanitarian umbrella.

4. Provide Income Generating Activity (IGA) and vocational training - both these areas of activity should be provided to every potential refugee, and humanitarian agencies should provide them to all adult refugees. 
5. Establish Age Friendly Spaces (AFS) for older people - every donor agency should include these on their implementation schedules and establish them at camp level.

6. Build awareness about older people and their abilities - older people are a resource, not a burden. They do not want sympathy, they only seek their due rights. Humanitarian agencies should ensure their dignity and rights, and provide needs- based health facilities, amusement and recreation activities, and positively encourage participation. Since their displacement, the mind-sets of older people have become such that they perceive themselves as 'a burden to all, abandoned, excluded, neglected or rejected everywhere.' A primary focus should be on mitigating these thoughts, and helping to restore the dignity of the older people that find themselves in this position.

Future research can collect detailed data with a bigger sample size on their gradual improvement of physical and mental health and wellbeing of older Rohingya refugees. One can investigate their socioeconomic and voluntary activates for their own communities. The coverage of AFS services and its utilization need systematic research for better understanding about the real scenario. Also one can compare the participation of older people in AFS between Rohingya camps and host communities.

\section{Conflict of Interest statement}

All authors declare here that there is no conflict of interest in their end.

\section{Acknowledgments}

The paper was part of the YPSA ageing project in Bangladesh. It was initially presented at the International Conference on the Rohingya Crisis in Comparative Perspective held during 4 - 5 July 2019, UCL in the United Kingdom (https://www.ucl.ac.uk/risk-disasterreduction/events/2019/jul/international-conference-rohingya-crisis-comparative-perspective) and authors gratefully acknowledge the comments of conference participants. We also express our gratitude to two anonymous reviewers for their constructive comments and suggestions to the paper. Authors would also like to thank Dr. Helen Findlay for her insightful thoughts and suggestions during the stage of conducting the research. 


\section{References}

ACAPS (2018). Rohingya Crisis: Pre-Monsoon Review. https://www.acaps.org/sites/acaps/files/products/files/20180319_acaps_npm_bangladesh_pre _monsoon_thematic_report_corrected.pdf (Accessed on 26 May 2020)

Baura, P., Molla, MH and Rahman, SH (2019). Rohingya Influx and Environmental Catastrophes in South-Eastern Bangladesh, Journal of Social Change 8:86-100.

BBS (2003). Bangladesh Bureau of Statistics, Ministry of Planning, Government Republic of Bangladesh, Dhaka.

BBS (2014). Cox's Bazar District Report, Bangladesh Bureau of Statistics, Ministry of Planning, Government Republic of Bangladesh, Dhaka.

Bhatia, A., Mahmud, A., Fuller, A., Shin, R., Rahman, A., Shatil, T., Sultana, M., Morshed, K., Leaning, J., and Balsari, S. (2018). The Rohingya in Cox's Bazar: When the Stateless Seek Refuge. Health and human rights 20(2):105-122.

Burton, A. and Breen, C. (2002). Older refugees in humanitarian emergencies. The Lancet, 360:s47-s48.

COAST (2018). Crisis within the Crisis. A study on impact of Rohingya influx on the host community, July 2018 and WFP with Partners, Refugee influx Emergency Vulnerability Assessment (REVA) - Technical Report, August 2018.

Dubus, N. (2018). Arriving old: A qualitative study of elder refugee women's self-perceptions of the first year of resettlement. Journal of Gerontological Social Work 61(4):393-410.

Heller, P.S. (1997). Ageing in the Asian —Tigers\| Challenges for fiscal policy. Working Paper of the International Monetary Fund 143. Washington.

HelpAge International (2019). Help Age International. https://www.helpage.org/what-wedo/emergencies/humanitarian-response/rohingya-crisis/ (visited 6 May 2019). 
Huang, C and Gough, K. (2019). Toward Medium-Term Solutions for Rohingya Refugees and Hosts in Bangladesh: Mapping Potential Responsibility Sharing Contributions, Canter for Global Development, CGD BRIEF, 2019.

Islam, MN, Nath, DC (2012). A Future Journey to the Elderly Support in Bangladesh, Journal of Anthropology, Article ID 752521, doi.org/10.1155/2012/752521.

Kabir, H. (1994). Local Level Policy Development to Deal with the Consequences of Population ageing in Bangladesh. United Nations, ESCAP, Thailand.

Kabir, M. (1991).Ageing in Bangladesh: Its Social, Economic and health Consequences. Proceedings of the Workshop on Dissemination of Current Statistics. Organized by Bangladesh Bureau of Statistics, Dhaka, Ministry Planning.

Kabir, M. (2003). Demographic and Economic Consequences of Ageing in Bangladesh, In Demographic Dynamics in Bangladesh. Center for Policy Dialogue, Dhaka Bangladesh.

Kabir, M. and M.A Salam. (1993). Ageing in Bangladesh: Its Social, Economic and Health Consequences. The elderly Population in Developed and Developing World: Policies, Problems and Perspectives, edited by P. Krishnan and K. Mahadevan. BR Publishing Corporation, Delhi, India.

Khan, H.T.A. (2014). Factors Associated with Intergenerational Social Support among Older Adults across the World, Ageing International 39:289-326.

Khan, H.T.A., Hussein, S. and Deane, J. (2017). Nexus Between Demographic Change and Elderly Care Need in the Gulf Cooperation Council (GCC) Countries: Some Policy Implications, Ageing International 42(4): 466-487.

Mahmood, S., Wroe, E., Fuller, A. and Leaning, J. (2017). The Rohingya people of Myanmar: health, human rights, and identity. The Lancet 389(10081):1841-1850.

Messner, N., Woods, A., Petty, A., Parmar, P., Leigh, J., Thomas, E., Curry, D., Venters, H., Gilbert, A., Nelson, T. and Lester, E. (2019). Qualitative evidence of crimes against humanity: the August 2017 attacks on the Rohingya in northern Rakhine State, Myanmar. Conflict and Health, 13(41):1-17.

Milton, A., Rahman, M., Hussain, S., Jindal, C., Choudhury, S., Akter, S., Ferdousi, S., Mouly, T., Hall, J. and Efird, J. (2017). Trapped in Statelessness: Rohingya Refugees in Bangladesh. International Journal of Environmental Research and Public Health 14(8):942. 
Rahman, KMM, Mohsin, MI and Tareque, I. (2009). Trends of Population Ageing from 19502050: A Comparative Study between Bangladesh and World, Pakistan Journal of Social Sciences 6(1): 6-10.

Rahman, M.M, Tareque, M.I. Rahman, K.M.M. and Islam T.M. (2007). Dimension of Population Ageing in Bangladesh. Middle East Journal of Age and Ageing 4(5): 17-22.

Relief Web International (2020). https://reliefweb.int/report/bangladesh/bangladesh-rohingya-

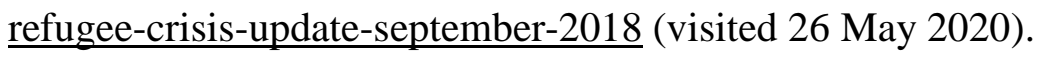

Saleheen, Mesbah-us. (2011). Ageing Population of Bangladesh: An Emerging Challenge edited Nurun Nabi in Bangladesh Population: Problems and Prospects. SEI Division, Planning Commission.

Singh, L., Arokiasamy, P., Singh, P.K. and others (2013). Determinants of Gender Differences in Self -Related Health Among Older Population: Evidence from India. Sage Open, https://doi.org/10.1177/2158244013487914 (accessed on 12 June 2020)

Solidarities International (2020) https://www.solidarites.org/en/press/one-year-into-therohingya-refugee-crisis-in-bangladesh/ (visited 26 May 2020).

Strong, J., Varady, C., Chahda, N., Doocy, S. and Burnham, G. (2015). Health status and health needs of older refugees from Syria in Lebanon. Conflict and Health 9(12):1-10.

Sullivan, D. (2020). Rohingya refugee camps are the next frontline in Covid-19 fight. https://www.refugeesinternational.org/reports/2020/4/29/rohingya-refugee-camps-are-thenext-frontline-in-covid-19-fight (accessed on 25 May 2020)

UNHCR (2019). Bangladesh Refugee Emergency, Population Factsheet Bangladesh. bgdcoim@unhcr.org (visited 5 May 2019).

Waite, L.J. (2004). Ageing, Health and Public Policy: Demographic and Economic Perspectives. Population and Development Review 30. The Population Council, New York.

UN (2017). World Population Ageing Report 2017. Department of Economic and Social Affairs, Population Division, United Nations, New York. 
UN (2018). Bangladesh 'disappointed' at lack of progress in alleviating plight of Rohingya, Prime Minister tells UN Assembly, https://news.un.org/en/story/2018/09/1021302 (Accessed on $6^{\text {th }}$ July 2020).

World Population Review (2020). Bangladesh population. https://worldpopulationreview.com/countries/bangladesh-population/ (Accessed on $25^{\text {th }}$ May 2020)

Table 1: Details of the respondents.

\begin{tabular}{|c|c|c|c|}
\hline \multicolumn{2}{|c|}{ Name of Camp } & \multirow{2}{*}{$\begin{array}{l}\text { Name of } \\
\text { Respondent } \\
\text { Jamila Bibi }\end{array}$} & \multirow{2}{*}{$\begin{array}{l}\text { Characteristics } \\
\text { Gender- Female; Age -70; Husband - Death; } \\
\text { Children-04 Sons \& 02 Daughters }\end{array}$} \\
\hline \multirow{4}{*}{$\stackrel{0}{2}$} & \multirow{2}{*}{ Camp-11 } & & \\
\hline & & Abu Taher & $\begin{array}{l}\text { Gender-Male; Age -61; Wife - alive; Children - } \\
01 \text { Son \& } 07 \text { Daughters }\end{array}$ \\
\hline & \multirow{2}{*}{ Camp-13 } & Gul Aser & $\begin{array}{l}\text { Gender- Female; Age -71; Husband - death; } \\
\text { Children-03 Daughters }\end{array}$ \\
\hline & & Syed Hossan & $\begin{array}{l}\text { Gender- Male; Age - 65; Wife- alive; Children-- } \\
02 \text { Sons \& } 04 \text { Daughters }\end{array}$ \\
\hline \multirow{4}{*}{$\underbrace{\infty}_{0}$} & \multirow{2}{*}{ Camp -11 } & Male Group & Total Participants -08 \\
\hline & & Female Group & Total Participants -08 \\
\hline & \multirow{2}{*}{ Camp-13 } & Male Group & Total Participants -08 \\
\hline & & Female Group & Total Participants -08 \\
\hline
\end{tabular}

Note: KIIs - Key Informant Interviews; FGDs - Focus Group Discussions

Source: Compiled by authors, 2019 
Table 2: YPSA's Contemporary Performance with Older People in Rohingya Refugee

\section{Camps}

\begin{tabular}{|c|c|c|}
\hline S.N & Performance of YPSA & No of Performance \\
\hline 01 & Data base of Older People & $\begin{array}{l}5114 \text { (Male: 2550, Female: } \\
\text { 2564) }\end{array}$ \\
\hline 02 & Primary Health Service Provided to Older People & 5948 \\
\hline 03 & Referrer to specialized service & 98 \\
\hline 04 & Home base care Service & 321 \\
\hline 05 & $\begin{array}{l}\text { Psychosocial Counselling, Refer \& Family member } \\
\text { refer }\end{array}$ & 3364 \\
\hline 06 & EYE Camp: 01 & $\begin{array}{l}\text { Patient-299, Operation }-44, \\
\text { Glass-72 }\end{array}$ \\
\hline 07 & Day Observation & $\begin{array}{l}\text { 03, International Women's } \\
\text { Day } 2018 \quad \& \quad 2019 \quad \& \\
\text { International Elderly Day- } \\
2018\end{array}$ \\
\hline 08 & WASH awareness to Older People & 911 \\
\hline 09 & Refer to Humanitarians services & 5948 \\
\hline 10 & $\begin{array}{l}\text { Age Friendly Kits (Hand Stick, Prayer mat, Torch } \\
\text { Light, } \\
\text { Medicine box, Umbrella, Sandal, Urine pot, } \\
\text { Commode chair) Distribution }\end{array}$ & 5590 \\
\hline 11 & Winter Cloth Distribution & 3100 \\
\hline 12 & AFS Management Committee Established & 02 (30 Members) \\
\hline
\end{tabular}




\begin{tabular}{|l|l|l|}
\hline S.N & Performance of YPSA & No of Performance \\
\hline 13 & WASH Committee Established & 02 (30 Members) \\
\hline 14 & Protection Group Established & 16 (240 Members) \\
\hline 15 & OP Representative & 36 \\
\hline 16 & Diabetic Awareness Session & 01 (250 Participants) \\
\hline 17 & Photi Pater Ashar6 & 01 (300 Participants) \\
\hline 18 & Kabi Ganer Ashor & 01 (250 Participants) \\
\hline 19 & DRR Training to OP & 16 (350 Participants) \\
\hline 20 & Complain Response of OP & 260 \\
\hline 21 & Torture Victim Identified \& Treatment & 200 \\
\hline
\end{tabular}

Source: YPSA - Ukhiya Office, 2019

\footnotetext{
${ }^{6}$ Ancient epic or story book, a reader loudly read the story and listener setting around side of reader. The story line are
} rhyme, the lines are interconnected and euphonically. 
Figure 1: It shows part of government distribution activity in the area.

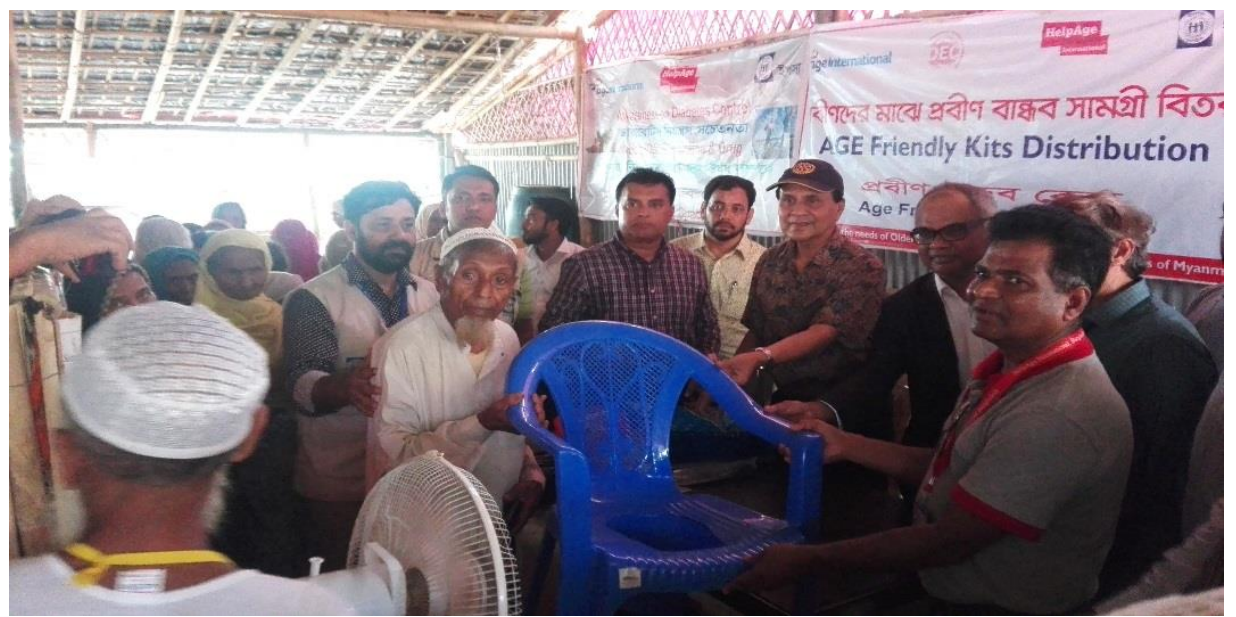

Ex. Cabinet Secretary Distribute Age Friendly Kits to Disable OP (Copy right: YPSA) 
Figure 2: Map: Rohingya influx area.

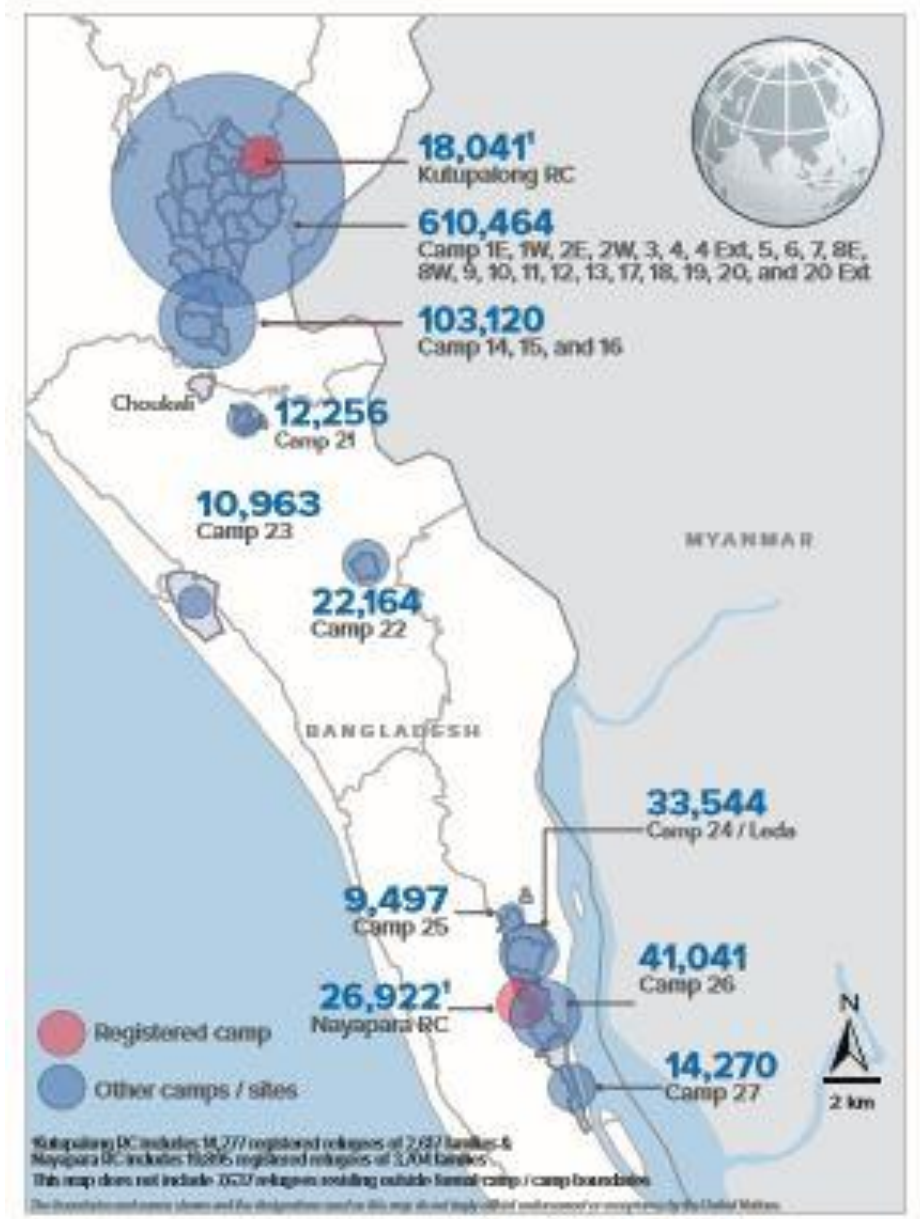

Source: UNHCR, 2019 
Figure 3: Rohingya peoples' attendance in an awareness session.

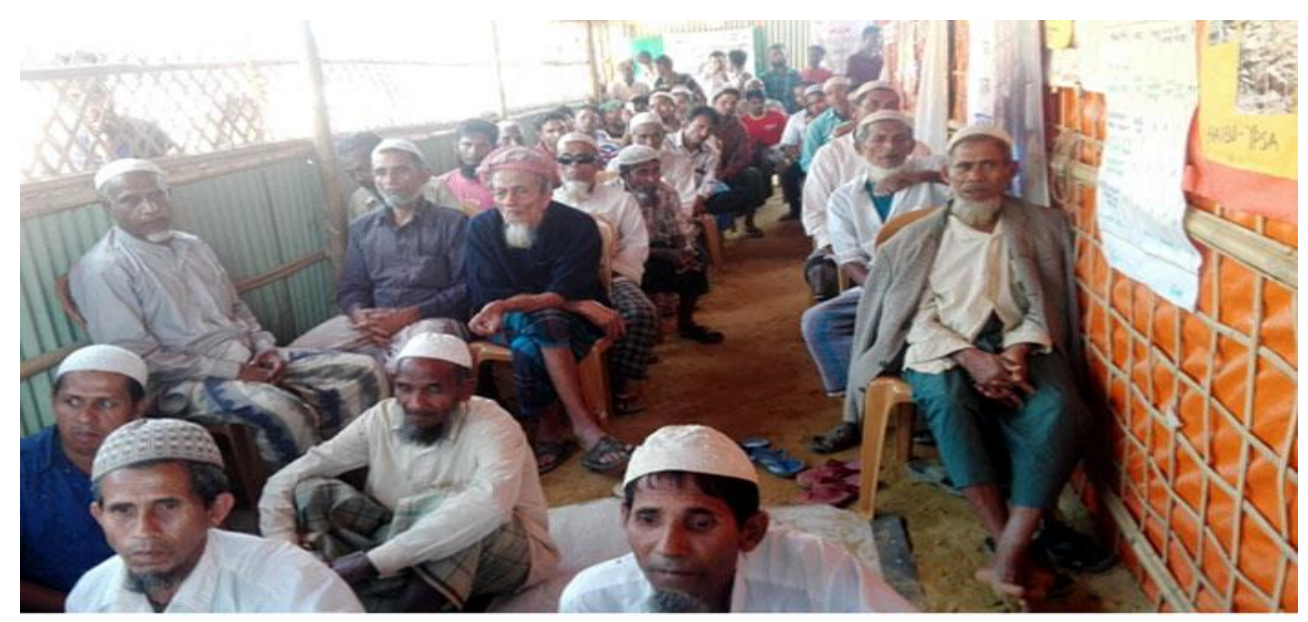

Awareness session on Diabetes - Control, Discipline, Diet \& Drug (Copy right: YPSA)

Figure 4: Healthcare services in the Rohingya camp.

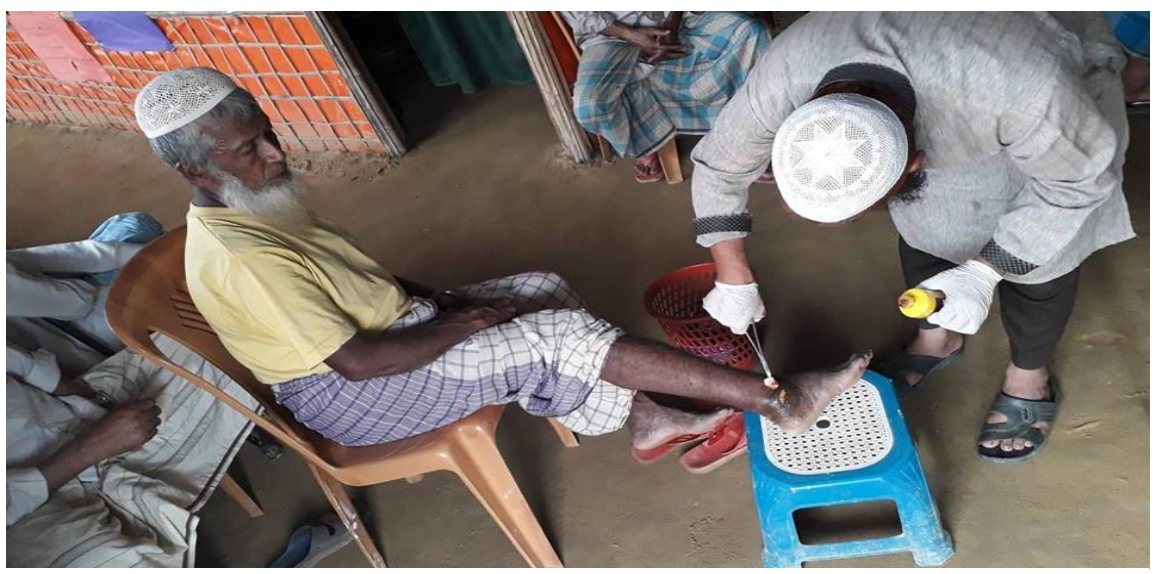

Health care services to Elderly People by registered doctor 
Figure 5: Recreational activities for Rohingya population.

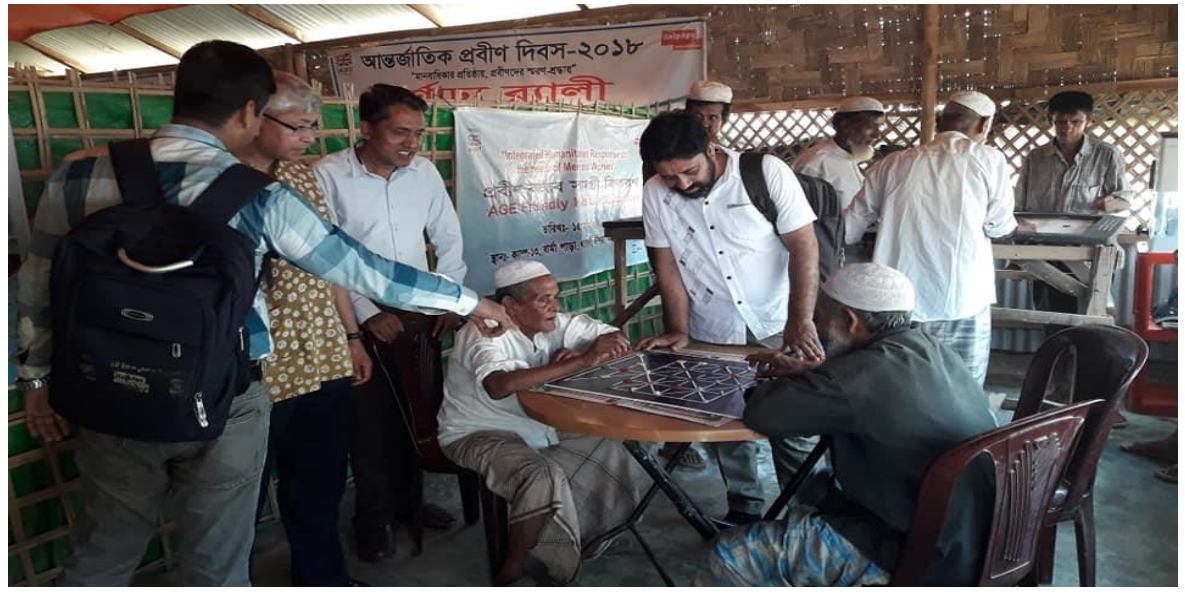

Recreation facility for Elderly People 


\section{Figure 6: Focus Group Discussion (FGD) with Rohingya older people in the camp.}

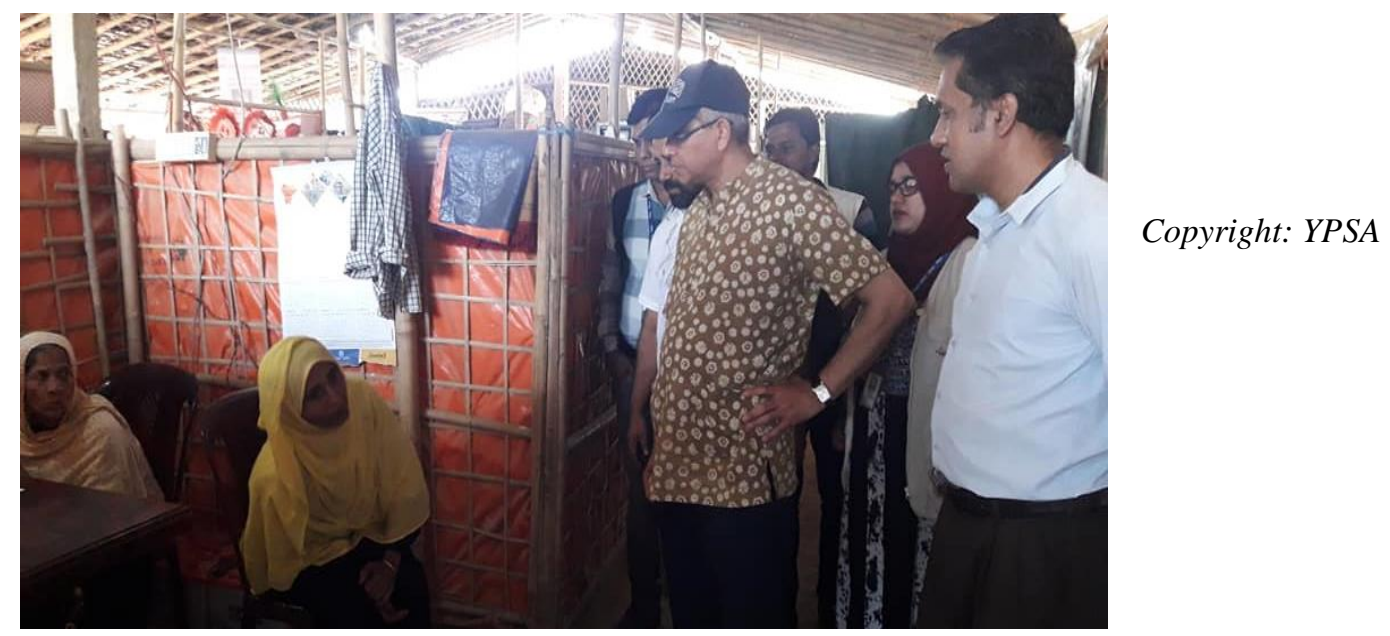

\section{Author's Biography}

Hafiz T.A. Khan is Professor of Public Health and Statistics at University of West London and is also an associated research fellow at the Oxford Institute of Population Ageing, University of Oxford in the UK. He earned a PhD in Demography from Edinburgh Napier University in collaboration with University of Dundee in 1996 and has conducted postdoctoral research in gerontology at the University of Oxford in 2005-06. His research interests include demography, gerontology and public health statistics. He has published articles in health and population related issues and has co-authored two books "Research Methods for Business and Social Science", Sage, 2007 and 2014. He can be contacted at hafiz.khan@uwl.ac.uk

Mohammed Arifur Rahman is Chief Executive, YPSA (Young Power in Social Action), Chittagong-4212, Bangladesh and PhD Fellow, Techno India University, India. ypsa_arif@yahoo.com 
Morshed Hossan Molla is Research and Monitoring Officer, YPSA (Young Power in Social Action), Chittagong-4212,Bangladesh. morshedgeo@yahoo.com

Mohammad Shahjahan is Deputy Director (Head)- Knowledge Management for Development (KM4D), YPSA (Young Power in Social Action), Chittagong - 4212, Bangladesh. jahanctg@gmail.com

Rifah B. Abdullah has completed undergraduate degree in Psychology and Neuroscience at University of Glasgow, Glasgow, Scotland, United Kingdom, rifahbin@ yahoo.co.uk 